\title{
Determine the Impact of Market-orientated Skill Training on Satisfaction and Effectiveness of Trainees in Technical and Vocational Training: A Case Study in Western Azarbaijan Province, Iran
}

\author{
Hassan Nalbandi ${ }^{1,2}$, S. Jafar Zonoozi ${ }^{3 *}$ \\ ${ }^{1}$ Department of Management, West Azarbaijan Science and Research Branch, Islamic Azad University, Urmia, IRAN \\ ${ }^{2}$ Department of Management, Urmia Branch, Islamic Azad University, Urmia, IRAN \\ 3 Asistant Professor of Economy and Management, Urmia University, Urmia, IRAN
}

*Corresponding Author: sj.zonoozi@urmia.ac.ir

Citation: Nalbandi, H. and Zonoozi, S. J. (2019). Determine the Impact of Market-orientated Skill Training on Satisfaction and Effectiveness of Trainees in Technical and Vocational Training: A Case Study in Western Azarbaijan Province, Iran. Dutch Journal of Finance and Management, 3(1), em0054. https://doi.org/10.29333/djfm/5871

Published: March 15, 2019

\begin{abstract}
The aim of this study was to determine the impact of market-orientated skill training on satisfaction and effectiveness of trainees in technical and vocational training, Western Azarbaijan province, Iran. The population was all trained trainees (700 individuals) of market-oriented courses in the department of technical and vocational training in Western Azerbaijan during 2015/03/21 to 2015/08/23. According to Morgan table, 250 individuals were randomly selected. A designed questionnaire by researcher was used to collect data. Data were analyzed using path analysis. The results revealed that skill training of market orientation had no significant effect on satisfaction and effectiveness of technical and vocational training, Western Azarbaijan province, Iran.
\end{abstract}

Keywords: market-orientated, skill training, technical and vocational training, satisfaction

\section{INTRODUCTION}

Nowadays, concerning to human resources and technical and professional skills is necessary, addressed on the conditions and the circumstances of performance of the labor market and the emergence of the knowledge-based economy (Mehr-mohammadi, 2002). Training of required human resources for technical and vocational training form was concerned in the communities since the late nineteenth and early twentieth centuries for a lot of countries.

Education was unprecedented spread following the developments in science and technology since World War II. As far as the development of technical and vocational training programs are the national goals of most countries, and it is one of the indicators of the success of each country, these developments are considered in industry, agriculture and services. Developments in these sectors are required to training of skilled manpower and efficient in technical and vocational fields which are proportional to the labor market (Bahreini, 2006). The most important requirement for the development of a country is the development of technical and vocational training as one of the determining factors in the growth and the development of the country is experienced human resources. There are different perspectives to technical and vocational training, in other words, there are differences in approach and definition of vocational training that creates different expectations to it (Babe, 2004 quoted by Salehi, 2004). 


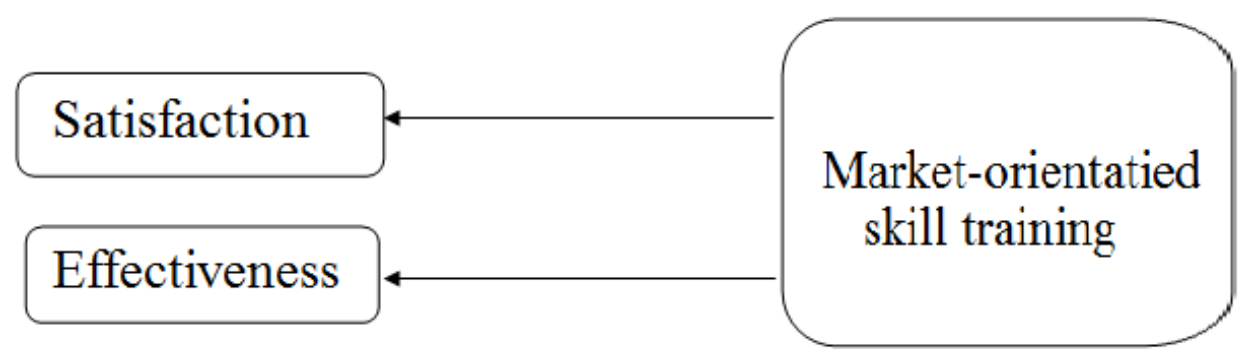

Figure 1. The conceptual model of research

On the other hand, it is necessary to be appropriate coordination between the offered training and the needs of the labor market. One of the major weaknesses in developing countries is to foster human resources like West, while the industrialized countries of the West have revised their education system regularly with a new technological-economic conditions, but this type of innovations are not visible in developing countries. As industry and other economic sectors should be attention to the rapid technological developments, technical and vocational training should fit their training standards strings quickly by improve technological advancements. For this reason, in the industrial countries feel the need for a new major in the industry to help technology improvement and there is ability to develop and revise curriculum and launch it in the field of industrial training centers and so on in the shortest possible time (Izadi, 2002).

One of the major challenges that policy makers and planners face still technical and vocational training systems in developing countries as well as developed countries is the ability to operate the concept of entanglement, and not exclusively and harmonious coexistence of standards and educational job values. The gap or separation between education and the world of work can be seen most of all particularly in developing countries that is one of the main deficiencies of vocational training in these countries (Roberts and Candida, 1985).

Since, one of the main criteria for the effectiveness of vocational training is the training capabilities in training human resources for the market; this phrase contains two main concepts. First, technical and vocational training must be trained human resources for those jobs that are more important than other jobs or to express better the labor market, second, technical and vocational training should be train those job who teach the knowledge and skills that are necessary to perform the job effectively. The common principle is that human resources training should be based on the market orientation. Usually, educational standards explain the objectives and content of training and fit to it the length of the course and the educational structure. These standards are the core of technical and vocational training on the one hand and content compliance with the respective labor market on the other side. Thus, this study seeks to answer the question whether market orientation skills training has a significant effect on satisfaction and effectiveness in technical and vocational training trainees in Western Azerbaijan province, Iran.

\section{METHODOLOGY}

The research method was descriptive. The population was all trained trainees (700 individuals) of marketoriented courses in the Department of technical and vocational training in Western Azerbaijan during 2015/03/21 to 2015/08/23. According to Morgan table, 250 individuals were randomly selected. A designed questionnaire by researcher was used to collect data. Data were analyzed using path analysis.

The study was performed after describing in detail to participants the introductory remarks about the gauges and the purpose of the test, how to response to tests. It can be noted that regarding to ethical considerations, they were assured that the information will be used only in the research and be protected from any abuse after obtaining the consent of the people and giving the necessary knowledge. Following questionnaires designed by researcher were used to measure the variables.

The questionnaire contained 23 questions that were assessed following items; 1-4) for measuring marketorientated, 5- 10) satisfaction, 11-14) effectiveness, 15-19) attitude and 20-23) life quality. Conceptual model of research is shown in Figure 1. Regard to the purposes of research, questions related to market-orientated, satisfaction and effectiveness were analyzed.

The validity of questionnaire was confirmed by professors and experts. Cronbach's alpha was used to determine reliability. The results showed that the Cronbach's alpha coefficient for market-oriented, satisfaction and effectiveness was $0.74,0.742$ and 0.75 , respectively that showed good reliability of measurement tool. Path analysis was used to analyze the data. 
Dutch Journal of Finance and Management, 3(1), em0054

Table 1. KMO and Bartlett test

Kaiser-Meyer-Olkin (KMO) measure of sampling adequacy

0.813

Bartlett test

\begin{tabular}{cc} 
chi - square approximation & 269.195 \\
\hline df & 15 \\
\hline Sig. & 0.000
\end{tabular}

Table 2. Matrix shares

\begin{tabular}{cccc}
\hline & Initial & Extracted & \\
\hline Satisfaction 1 & 1.000 & 0.477 \\
\hline Satisfaction 2 & 1.000 & 0.358 \\
\hline Satisfaction 3 & 1.000 & 0.379 & 0.494 \\
\hline Satisfaction 4 & 1.000 & 0.524 \\
\hline Satisfaction 5 & 1.000 & 0.407 \\
\hline Satisfaction 6 & 1.000 & \\
\hline
\end{tabular}

Extraction method: principal component analysis

Table 3. Total explained variance

\begin{tabular}{cccccc}
\hline \multirow{2}{*}{ Component } & \multicolumn{3}{c}{ Primary special quantities } & \multicolumn{2}{c}{ Squares sum of extractive loads } \\
\cline { 2 - 5 } & Total & Variance\% & Total & Variance\% \\
\hline 1 & 0.832 & 43.974 & 43.974 & 2.638 & 43.974 \\
\hline 2 & 0.777 & 13.873 & 57.846 & & \\
\hline 3 & 0.631 & 10.523 & 70.796 & & \\
\hline 4 & 0.590 & 9.838 & 91.157 & \\
\hline 5 & 0.531 & 8.843 & 100 & & \\
\hline 6 & & & & \\
\hline
\end{tabular}

Extraction method: principal component analysis

Table 4. Matrix of "a" component

\begin{tabular}{ll}
\hline & $\mathbf{1}$ \\
\hline Satisfaction 1 & 0.691 \\
\hline Satisfaction 2 & 0.597 \\
\hline Satisfaction 3 & 0.619 \\
\hline Satisfaction 4 & 0.703 \\
\hline Satisfaction 5 & 0.728 \\
\hline Satisfaction 6 & 0.637 \\
\hline
\end{tabular}

Table 5. The results of Path analysis

\begin{tabular}{cccc}
\hline & Estimation (Regression path coefficient) & t statistics & Sig \\
\hline Satisfaction $\rightarrow$ market orientation & 0.291 & 1.040 & 0.298 \\
\hline
\end{tabular}

\section{RESULTS}

In this study, market-oriented skill training on satisfaction was investigated. Exploratory factor analysis of variable satisfaction is provided in Table 1. the adequacy of the sample in Kaiser-Meyer-Olkin (KMO) and Bartlett test should be more than 0.7 that have been observed in this variable and was more than 0.7 (Table 1). To select the number of components, specific amount value was used that components should be higher than 1.4. Also, the default value was considered 0.30 to determine the appropriate factors (Table 2).

As can be seen in Table 3, the cumulative percentage of the total variance was set equal to 44.150 for two factors before and after the rotation. As can be observed the first factor include the greatest variance before rotation, and this amount decreases, respectively. While after the rotation, this variance determine in terms of its importance. In Table 2, we observed in rotation and in specific amount that all factors have specific value more than 1.4 indicating the significant importance of two factors.

Then, as shown in Table 4, the first repetition of principal component matrix after rotation can be observed.

The coefficient estimation of the structural equation modeling (0.291) in Table 5 showed that $t$ statistic was 1.040. As far as, $t$ statistic should be more than \pm 1.96 , it can be noted that there was no significant relationship between market-oriented skills training and satisfaction.

The next objective of study was market-oriented skills training effect study on effectiveness. Meyer-Olkin $(\mathrm{KMO})$ and Bartlett indices are used to determine the adequacy of the sample, which should be more than 0.7 that regarding to Table 6, it can be observed these cases are considered (Table 6). 
Table 6. KMO and Bartlett test

Kaiser-Meyer-Olkin (KMO) measure of sampling adequacy

0.743

Bartlett test chi - square approximation

272.020

\begin{tabular}{cc} 
chi - square approximation & 272.020 \\
\hline $\mathrm{df}$ & 6 \\
\hline Sig. & 0.000
\end{tabular}

Table 7. Matrix shares

\begin{tabular}{ccc}
\hline & Initial & Extracted \\
\hline Satisfaction 1 & 1.000 & 0.508 \\
\hline Satisfaction 2 & 1.000 & 0.479 \\
\hline Satisfaction 3 & 1.000 & 0.636 \\
\hline Satisfaction 4 & 1.000 & 0.684 \\
\hline
\end{tabular}

Extraction method: principal component analysis

Table 8. Total explained variance

\begin{tabular}{cccccc}
\hline \multirow{2}{*}{ Component } & \multicolumn{3}{c}{ Primary special quantities } & \multicolumn{2}{c}{ Squares sum of extractive loads } \\
\cline { 2 - 6 } & Total & Variance \% & Total & Variance \% \\
\hline 1 & 2.307 & 57.670 & 57.670 & 2.307 & 57.670 \\
\hline 2 & 0.742 & 18.554 & 76.225 & & \\
\hline 3 & 0.526 & 13.141 & 89.366 & & \\
\hline 4 & 0.425 & 10.643 & 100 & \\
\hline
\end{tabular}

Extraction method: principal component analysis

Table 9. Matrix of "a" component

\begin{tabular}{lll}
\hline & 1 \\
\hline Effectiveness 1 & 0.713 \\
\hline Effectiveness 2 & 0.692 \\
\hline Effectiveness 3 & 0.797 \\
\hline Effectiveness 4 & 0.827 \\
\hline
\end{tabular}

Table 10. The results of Path analysis

\begin{tabular}{lcccc}
\hline & Estimation (Regression path coefficient) & t statistics & Sig \\
\hline Effectiveness $\rightarrow$ market orientation & 0.049 & 0.433 & 0.665 \\
\hline
\end{tabular}

As can be seen in Table 8, the cumulative percentage of the total variance was set equal to 57.670 for two factors before and after the rotation. As can be observed the first factor include the greatest variance before rotation, and this amount decreases, respectively. While after the rotation, this variance determine in terms of its importance. In Table 7, we observed in rotation and in specific amount that all factors have specific value more than 1.4 indicating the significant importance of two factors.

Based on Table 9, the first repetition of principal component matrix after rotation can be observed.

Regard to Table 10, the coefficient estimation of the structural equation modeling and $t$ statistic was 0.049 and 0.433 , respectively. As far as, $\mathrm{t}$ statistic was more than \pm 1.96 , it can be noted that there was no significant relationship between market-oriented skills training and effectiveness.

\section{CONCLUSION}

The aim of this study was to investigate determine the impact of market-orientated skill training on satisfaction and effectiveness of trainees in technical and vocational training, Western Azarbaijan province, Iran The results showed that there was no significant relationship between market-oriented training skills and satisfaction. To explain these findings, it can be said that the market can not be a reason to increase the satisfaction of training apprentices, because the trainee is in the learning phase and has not yet entered to the job market. Satisfaction has many differences with job satisfaction in the learning stage. And in this study, it is proved that the market orientation of training had no effect on satisfaction from education, perhaps enhance job satisfaction in the future. Because this training, improve works method of trainee to boost his business. Also, there was no significant effect between market-oriented skills training and effectiveness.

To explain these findings, we can say that there was no significant relationship between them because of to be trainee the subjects of study and do not enter into business. Effectiveness is one of purely economic components. As mentioned above, this concept considers part of the economy science. So, it is defined in this stage as a person entering the job market. Certainly, market-oriented education will increase the effectiveness of work in the future, but as the trainees are in learning situation, they it did not fully touch the situation yet and ignored it. According 
to the results, it is recommended to managers and teachers working in the technical and vocational training department that think to implementation of the factors that increase the trainees' satisfaction. Also technical and vocational training department through contracts with small and large industries in the real environment appoint trainees to temporary jobs and increase usefulness sense of learning job by receiving their wages.

\section{REFERENCES}

Bahreini, S. S. (2006) Analytical investigation of the Reengineering implementation of Business Process in higher education. Journal of honest thoughts, (23).

Izadi, S. and Saffar-heidari, H. (2002). The employment status of technical and vocational training in Mazandaran province in the socio-economic development program. Journal of Social and Human Sciences, Year 4.

Mehr-mohammadi, M. (1999). An analytical report of the Fifth International Conference of UNESCO, research on educational issues. The Iranian Society of Education, Ministry of Education.

Robert, D. H. and Candida, G. B. (1985). The woman Entrepreneur: Starting, Financing, and Managing a successful New Business, Lexington books, p. 18.

Salehi, A. (2004). Investigating factors affecting employment of technical and vocational trainees (case study: Mazandaran). Journal of bumanities and social sciences, (4). 